\title{
ANNOTATION
}

\section{The Faculty of Observation}

Few, if any, of our readers will cavil at the statement that, amongst the characteristics that separate the master clinician from those of the rank and file, that of accurate and penetrating observation deservedly takes a high place. While the whole training of the medical man aims at developing this faculty it is given to only a few to excel. Of this select class the late Sir Rickman Godlee was one. Our readers are familiar with the charm of his style as evidenced in two articles contributed to this journal, one on Wharton Jones (1921) and the other on Sir Jonathan Hutchinson (1925). A further biography, that of Sir William Bowman, was under discussion but fate willed otherwise. Sir Rickman, like all really busy men, could find time for something outside his daily work, and it may not be known to all that he was a competent naturalist and archaeologist. In the all too brief period that followed his retirement from the practice of his profession he contributed a series of articles to the Whitchurch Parish Magazine (we wish that all parish magazines contained as interesting material) on the archaeology, natural history, etc., of a very interesting part of the country. These were not intended for any wider publication, but Lady Godlee has had them published as a volume with excellent photographic illustrations (two, and these of particularly high technical quality, by another contributor to our columns, Sir William Lister).* The resulting volume is one we cordially recommend to our readers, both for its intrinsic interest, and the light it throws on the author's capacity for observation outside his profession, in which it must be remembered he reached the highest honours.

It has been said that it does not matter much what a man's work is like, but it matters very much what his hobbies are. Gamekeepers have trained their observation at their own particular job so highly that at times they almost appear to the uninitiated as conjurers; but their visual acuity, as tested by the stationary test letters at six metres, will be found to be no better than that of anyone else, and may even be much worse. Our speciality is a comparatively narrow one and we would all benefit by taking up some form of outside interest, preferably one assisting in the development of the invaluable faculty of observation. Archaeology is not a bad hobby for a professional man. He may spend his spare time in tracking ancient roads or exploring ruined sites and in each

" A Village on the Thames," by Rickman J. Godlee, George Allen \& Unwin, Ltd., London. 1926. 
case trained powers of observation will be of much assistance to him. Should he take to the more sedentary hobby of digging out facts from the public records, let us hope that he will not have the misfortune that is said to have befallen one of his class, who was engaged in genealogical research and who tracked a supposed ancestor through certain documents only to find the ominous sentence sus. per coll. appended at the bottom of the record. His worthy forebear had been hanged!

\section{ROYAL SOCIETY OF MEDICINE-SECTION OF OPHTHALMOLOGY}

THE opening meeting of the Section of Ophthalmology took place at the house of the Royal Society of Medicine, on Friday evening, ()ctober s.

Several interesting cases were shown, notably one by Mr. Hine, of neuro-fibromatosis of the right upper lid, a case of electric retinitis by Mr. Hugh Thompson, a case by Mr. Humphrey Neame of interstitial keratitis with deep corneal striation. Mr. Mayou showed a case of " ? pemphigus," also a case of massive exudation with detachment of the retina.

Afterwards, the retiring President, Sir Arnold Lawson, inducted the new President, Mr. Ernest Clarke, into the Chair, with a few well-chosen remarks. The address of the President contained a review of the progress made in ophthalmology in the last halfcentury, during most of which time he himself was actively engaged in the practice of this branch of medicine.

He referred to the introduction of antiseptics, and more especially to the use of the local anaesthetics, such as cocain.

It was just before this period that Donders published his work on refraction in English, and Mr. Clarke mentioned that as a return compliment, when he published his work on refraction in 1913, he did so in Dutch.

Among other things mentioned was the increasing attention being paid to errors of refraction, even small ones, and muscle balance, and emphasis was laid on the need for careful refraction work, and use of the cycloplegics. Mr. Clarke then went on to deal with the evils of chronic septic infection, and how many eye conditions were really due to this cause.

A review of some of the modern methods of treatment concluded this interesting address.

In moving a vote of thanks to the President, Mr. Treacher Collins congratulated the President on attaining his present position, and proposed a vote of thanks for the lucid address he had given. 
Mr. Cyril Walker, in seconding, hoped that the President's long experience would enable him to give valuable aid in the discussion of cases that might come before the Section.

Dr. Rayner Batten showed a series of drawings of Tay's choroiditis.

\section{NORTH OF ENGLAND OPHTHALMOLOGICAL SOCIETY}

AT the Annual Meeting of the North of England Ophthalmological Society the following members were elected to the Council for the Session 1926-192 1 :-President : Mr. Edgar Stevenson, Liverpool; Vice-President: Mr. H. Horsman McNabb, Manchester; Members of Council: Mr. T. Milnes Bride, Mr. H. Haward Bywater; Treasurer: Mr. S. D. Lodge; Secretary: Mr. Percival J. Hay.

The Local Secretaries are as follow: Mr. W. H. Kiep, Bradford; Mr. Harry Lee, Leeds; Mr. Horace Mather, Liverpool; Mr. T. Milnes Bride, Manchester; Mr. J. S. Arkle, Newcastle; Mr. Percival J. Hay, Sheffield.

At the six meetings which were held during the Session the following papers were read: "Two cases of sympathetic disease associated with evisceration and insertion of Mules' globe" (Mr. J. Gray Clegg). "An alternative to complete excision of the lacrymal sac" (Mr. H. Horsman McNabb). "A new method of treating hypopyon and other infective ulcers" (Mr. Percival J. Hay). "The differential diagnosis of cupping of the optic disc", (Mr. Harry Lee). "van Millingen's operation" (Mr. W. H. Kiep). "The treatment of hypopyon ulcers by chauffage" (Mr. Edgar Stevenson). "Operative treatment of acute dacryocystitis" (Mr. G. II. Pooley). "Retrobulbar neuritis and associated conditions" (Mr. A. S. Percival).

About 168 cases were shown during the Session. Among those of special interest may be mentioned a case of cerebral amaurosis. Both eyes appeared to be normal, but there was entire loss of vision. As evidence that the case was not wholly functional, and that there was some organic disturbance of the nervous system, there was increased muscle tone. The opinion was expressed that the case was one of anaemic degeneration of the cerebro-spinal cord, with functional symptoms super-added. A case of tuberculous choroiditis in both eyes showed a very striking symmetrical disposition of the lesions. There were two cases of congenital naevus in two girls aged respectively 16 and 19 years, involving, in the first case, the right lower lid, cheek, and soft palate, and, in the second case, the left temporal region and the 
left external canthus. The first had been treated in the Light Department of the Hospital, and the second had been treated repeatedly by electrolysis, but no improvement was shown in either case. There was a beautiful case of metallic foreign body retained in the eye for ten months without disturbance of vision, which was $6 / 9$. There was an unusual case of ophthalmic migraine, in which the patient had had five attacks, all of them accompanied by severe headaches, nausea, and diplopia, the latter being. intensified with each successive attack. A Mooren's ulcer was shown which had been successfully treated with the actual cautery, and several cases of obstinate keratitis which had been successfully treated with applications of artificial sunlight. Similarly a case of chronic keratitis which had resisted all the usual methods of treatment, but yielded to peritomy, the vision improving in the course of two years from fingers at six feet to $6 / 18$ and J.1. A case of Benson's disease was shown, being the second case of this rare disease having been shown at the meetings of the Society; the previous one was seen last year. A case of unusual interest was presented by a healthy boy, aged 11 years, who suddenly lost the sight of the right eye while walking in the street. The fundus showed obstruction of the central artery, with a cherry-red spot surrounded by oedema. This was followed afterwards by atrophy of the optic disc and sclerosis of the retinal vessels. Two brothers were shown with optic atrophy marked by rapid onset, in one at the age of 9 years, and in the other at 26 years. It was considered that they were probably of the hereditary type.

Among pathological specimens shown, there was a rare case of primary tubercle of the optic nerve with microscopic sections; a case of Mooren's ulcer with microscopic sections; a macroscopic specimen of a serous cyst of the orbit, with microscopic drawings of a similar cyst.

\section{THE ASSOCIATION OF DISPENSING OPTICIANS}

THE Association of Dispensing Opticians has recently been formed and eleven well-known firms have already been admitted to membership; the headquarters are at 439-441, Oxford Street, London.

The main principles of the Association are twofold: to safeguard the interests of dispensing opticians, and to ensure to the medical profession an efficient optical dispensing service. Membership is confined strictly to those engaged solely in optical dispensing work and their employees; and in no circumstances is an optician who professes or practises sight-testing admitted to membership in any grade. Four grades of membership, each of which carries a certificate are as follows: Grade A, employers; 
Grade B, managers; Grade C, assistants; Grade D, craftsmen. There are two grades of Associate membership for those under the age of 21 years. Lectures and classes are to be held for the instruction of members and examinations are to take place periodically so that members may pass from one grade to a higher. The Association is precluded from engaging in any wage questions or trade disputes.

The main details of the attempt on the part of the sight-testing opticians to obtain a Royal Charter will be fresh in the minds of our readers. The formation of the Association of Dispensing Opticians is a direct result of this attempt and is the best possible answer. An opportunity is now offered to those who clamoured for a charter in order to improve the status of the opticians to help in bringing this about, by giving up their sight-testing and becoming members of this Association.

\section{ABSTRACTS}

\section{I.-NEUROLOGY}

(1) Villard, H. (Montpellier.)-The Marcus Gunn phenomenon' (Le phénomène de Marcus Gunn.) (Synergie fonctionelle entre l'abaissement de la mâchoire et l'élévation de la paupière supérieure.) Arch. d'Ophtal., September, 1925.

(1) With a typical example of this syndrome as a text, Villard has written an excellent paper in the preparation of which he has referred to all or nearly all the records published since Gunn's case was presented to the Ophthalmological Society of the United Kingdom. This anomaly is variously known as the phenomenon or syndrome of Marcus Gunn, the jaw-winking syndrome, or, in France, mâchoire à clignement.

Villard's case, a healthy man, aged 28 years, was subjected tona thorough examination which, however, threw no light on the aetiology or pathogenesis of the "bizarre anomalie."

The value and interest of Villard's communication lie chiefly in the collective information which his study and analysis of published cases has enabled him to furnish. The phenomenon, first observed and described by Gunn has been subsequently studied by many. Villard has collected 92 reported cases, 93, including the example described by him. As Gunn's case was reported in 1883, a total of 93 in more than 40 years shows that the condition is very uncommon, "a pathological curiosity" according to the writer. 